\title{
ANALISIS PENYEBAB BANJIR KELURAHAN TANJUNG DUREN UTARA
}

\author{
Julian Sulistyo ${ }^{1}$ dan Wati Asriningsih Pranoto \\ ${ }^{1}$ Program Studi Sarjana Teknik Sipil, Universitas Tarumanagara, Jl. Letjen S. Parman No.1 Jakarta \\ julian.325160128@stu.untar.ac.id \\ ${ }^{2}$ Program Studi Sarjana Teknik Sipil, Universitas Tarumanagara, J1. Letjen S. Parman No.1 Jakarta \\ watip@ft.untar.ac.id
}

Masuk: 07-07-2020, revisi: 08-08-2020, diterima untuk diterbitkan: 02-11-2020

\begin{abstract}
Flood is a catalysm that occurs due to various factors. Factors causing floods in urban areas that we know in general are lack of water absorption, poor urban planning systems, water delivery from other areas, the amount of garbage in the drainage channels and high rainfall. Lots of losses caused by floods, ranging from disruption of the activities of surrounding residents to damage to public and private facilities. Tanjung Duren Utara Village has been flooded three times during January 2020. This journal aims to find out the factors that cause floods in North Tanjung Duren Village so that solutions can be found. For that there are a number of things that need to be analyzed which is rainfall, drainage capacity and condition of existing drainage. Topography of the area is a sunken lowland so has flood potential. After all the analyzes have been done it can be concluded that the flooding in Tanjung Tanjung Duren Utara Village was caused by the lack of existing canals capacity, topography, garbage, and the sediment at the bottom of the channel.
\end{abstract}

Keywords: flood; drainage; rainfall; North Tanjung Duren.

\begin{abstract}
ABSTRAK
Banjir merupakan bencana alam yang terjadi karena berbagai faktor. Faktor penyebab banjir di wilayah perkotaan yang kita ketahui secara umum adalah kurangnya resapan air, sistem tata ruang yang kurang baik, kiriman air dari wilayah lain, banyaknya sampah di saluran drainase dan curah hujan tinggi. Banyak sekali kerugian yang ditimbulkan akibat banjir, mulai dari terganggunya aktivitas warga sekitar hingga kerusakan pada fasilitas umum maupun pribadi. Di wilayah Kelurahan Tanjung Duren Utara tercatat sudah tiga kali mengalami banjir selama bulan Januari 2020. Jurnal ini bertujuan untuk mengetahui faktor yang menyebabkan terjadinya banjir di daerah Tanjung Duren Utara sehingga bisa dicari solusinya. Untuk itu ada beberapa hal yang perlu dianalisis yaitu curah hujan, kapasitas saluran dan keadaan saluran eksisting. Kontur daerah yang ditinjau merupakan dataran rendah yang berbentuk cekung sehingga memiliki potensi banjir. Setelah semua analisis dilakukan dapat disimpulkan bahwa banjir di kawasan Tanjung Duren Utara disebabkan oleh kurangnya kapasitas saluran eksisting, kontur wilayah, sampah dan sedimen di dasar saluran.
\end{abstract}

Kata kunci: banjir; drainase; curah hujan; Tanjung Duren Utara.

\section{PENDAHULUAN}

Tanjung Duren Utara merupakan Kelurahan yang terletak di Kecamatan Grogol Petamburan, Jakarta Barat, Daerah Khusus Ibukota Jakarta, Indonesia. Di Kelurahan Tanjung Duren Utara sebagian besar daerahnya merupakan pemukiman dan objek perekonomian. Namun objek ini terkena genangan air dengan jangka waktu yang cukup lama pada periode 1 Januari 2020 sampai dengan 3 Januari 2020. Peta sebaran titik banjir di Kelurahan Tanjung Duren Utara dapat dilihat pada Gambar 1 berikut. 


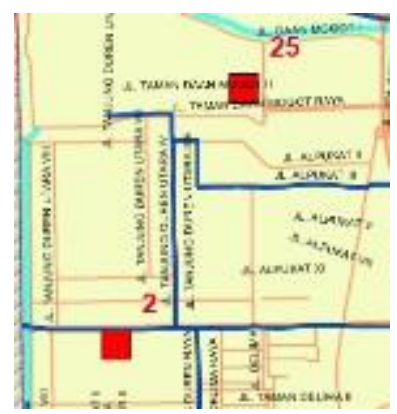

Gambar 1. Peta sebaran titik banjir genangan Kelurahan Tanjung Duren Utara (Sumber: Suku Dinas Sumber Daya Air Kota Jakarta Barat, 2020)

Permasalahan pada jurnal ini dirumuskan sebagai berikut:

- Apakah kapasitas saluran eksisting dapat menampung debit air dengan curah hujan yang terjadi pada periode 2010 sampai dengan 2019?

- Periode ulang berapa yang digunakan dalam perhitungan debit saluran?

- Apakah kontur di daerah yang tergenang menjadi penyebab terjadinya genangan?

- Apa penyebab genangan air bisa terjadi di Kelurahan Tanjung Duren Utara?

Tujuan dari penelitian ini adalah menganalisis penyebab banjir yang terjadi di Kelurahan Tanjung Duren Utara sehingga bisa dicari solusinya.

\section{Drainase}

Drainase adalah suatu cara pembuangan kelebihan air yang tidak diinginkan pada suatu daerah, serta cara penanggulangan akibat yang ditimbulkan oleh kelebihan air. Maksud dan tujuan drainase adalah membuang air di atas permukaan tanah yang berlebihan atau menurunkan atau menjaga muka air tanah agar tidak terjadi genangan, sehingga akibat negatif dengan adanya genangan dapat dihindari (Rachmawati).

\section{Pemilihan fungsi distribusi}

Pemilihan fungsi distribusi dapat diuji dengan uji kecocokan menggunakan metode pengujian dan dengan confidence interval tertentu dapat menggunakan Metode Chi-Square dan Metode Kolmogorov-Smirnov sebagai berikut (SNI 2415:2016):

- Chi-Square

Uji statistik ini berdasarkan pada bobot jumlah kuadrat perbedaan antara pengamatan dan teoritisnya yang dibagi dalam kelompok kelas. Uji kecocokan ini dapat dilihat pada persamaan:

$$
X^{\frac{k}{(i=1)}}=\frac{(O i-E i)^{2}}{E i}
$$

Dengan $X^{\frac{k}{(i=1)}}=$ parameter chi-square terhitung, $\mathrm{k}=$ jumlah sub kelompok, $\mathrm{Oi}=$ jumlah nilai pengamatan pada sub kelompok ke I, Ei = jumlah nilai teoritis pada sub kelompok ke i.

- Kolmogorov-Smirnov

Uji kecocokan ini adalah uji kecocokan "non parametric" karena tidak mengikuti distribusi tertentu. Uji ini menghitung besarnya jarak maksimum secara vertikal antara pengamatan dan teotitisnya dari distribusi sampelnya. Perbedaan jarak maksimum untuk Kolmogorov - Smirnov tertera pada Persamaan:

$$
\operatorname{Dn}=\max |\mathrm{P}(\mathrm{x})-\mathrm{Po}(\mathrm{x})|
$$

Dengan $\mathrm{Dn}=$ jarak maksimum antara pengamatan dan teoritisnya, $\mathrm{P}(\mathrm{x})=$ probabilitas dari sampel data, $\mathrm{Po}(\mathrm{x})=$ probabilitas dari teoritisnya.

\section{Hujan rencana}

Ada empat jenis distribusi yang banyak digunakan dalam menghitung curah hujan rencana yaitu:

- Distribusi Normal

Persamaan distribusi normal dapat dilihat sebagai berikut: 


$$
X_{t}=\bar{X}+z \cdot S_{x}
$$

Dengan $X_{t}=$ curah hujan rencana $(\mathrm{mm} / \mathrm{hari}), \bar{X}=$ curah hujan maksimum rata-rata $(\mathrm{mm} / \mathrm{hari}), \mathrm{S}_{\mathrm{x}}=$ standar deviasi, $\mathrm{Z}=$ faktor frekuensi.

- Distribusi Log Normal

Persamaan distribusi log normal dapat dilihat sebagai berikut:

$$
\log X_{t}=\bar{X}+K_{t} \cdot S_{x}
$$

Dengan $\mathrm{X}_{\mathrm{t}}=$ curah hujan rencana $(\mathrm{mm} / \mathrm{hari}), \bar{X}=$ curah hujan maksimum rata-rata $(\mathrm{mm} / \mathrm{hari}), \mathrm{S}_{\mathrm{x}}=$ standar deviasi, $\mathrm{K}_{\mathrm{t}}=$ standar variabel untuk periode ulang.

- Log Pearson III

Persamaan distribusi log pearson III dapat dilihat sebagai berikut:

$$
\log \bar{X}=\frac{\sum_{i=1}^{\mathrm{n}} \log \left(\mathrm{X}_{\mathrm{i}}\right)}{\mathrm{n}}
$$

Dengan $\log \bar{X}=$ harga rata-rata logaritmik (mm/hari), $\mathrm{X}_{\mathrm{i}}=$ nilai curah hujan (mm/hari), $\mathrm{n}=$ jumlah data.

- Gumbel

Persamaan distribusi gumbel dapat dilihat sebagai berikut:

$$
\mathrm{t}=-\mathrm{X}+\frac{\left(\mathrm{Y}_{\mathrm{t}}-\mathrm{Y}_{\mathrm{n}}\right)}{\mathrm{S}_{\mathrm{n}}} \times \mathrm{S}_{\mathrm{x}}
$$

Dengan $\mathrm{X}_{\mathrm{t}}=$ curah hujan rencana (mn/hari), $\bar{X}=$ curah hujan maksimum rata-rata (mm/hari), $\mathrm{S}_{\mathrm{x}}=$ standar deviasi, $\mathrm{Y}_{\mathrm{t}}=$ reduced variable, $\mathrm{Y}_{\mathrm{n}}=$ reduced mean, $\mathrm{S}_{\mathrm{n}}=$ reduced standard deviation.

\section{Intensitas hujan}

Intensitas curah hujan adalah ketinggian curah hujan yang terjadi pada suatu kurun waktu dimana air tersebut berkonsentrasi (Lubis) Analisis intensitas curah hujan ini dapat diproses dari data curah hujan yang telah terjadi pada masa lampau. Menurut Dr. Mononobe jika data curah hujan yang ada hanya curah hujan harian. Rumus yang digunakan:

$$
\mathrm{I}=\frac{\mathrm{R}_{24}}{24}\left(\frac{24}{\mathrm{t}_{\mathrm{c}}}\right)^{\frac{2}{3}}
$$

Dengan I = intensitas hujan $(\mathrm{mm} / \mathrm{jam}), \mathrm{tc}=$ lamanya curah hujan $(\mathrm{jam}), \mathrm{R} 24=$ curah hujan maksimum dalam 24 jam (mm).

\section{Koefisien Limpasan (C)}

Limpasan merupakan gabungan antara aliran permukaan, aliran-aliran tertunda pada cekungan-cekungan dan aliran bawah permukaan (sub surface flow) (Suripin). Nilai Koefisien Limpasan bias dilihat pada Tabel 1 sebagai berikut:

Tabel 1. Koefisien Limpasan

\begin{tabular}{lcc}
\hline Tata Guna Lahan & Karakteristik & Koefisien Limpasan $(\mathrm{C})$ \\
\hline Pusat bisnis dan perbelanjaan & & 0,9 \\
Industri & Penuh & 0,8 \\
& 20 rumah/ha & 0,48 \\
\multicolumn{1}{c}{ Perumahan (kepadatan sedang - tinggi) } & 30 rumah/ha & 0,55 \\
& 40 rumah/ha & 0,65 \\
& 50 rumah/ha & 0,75 \\
Perumahan (kepadatan rendah) & 10 rumah/ha & 0,4 \\
Taman & Daerah datar & 0,3 \\
Parkir & & 0,95 \\
\hline
\end{tabular}

(Sumber: Yosef Haryono, 2016) 


\section{Debit rancangan metode rasional}

Metode ini dapat menggambarkan hubungan antara debit limpasan dengan besar curah hujan secara praktis berlaku untuk luas DAS hingga 5.000 hektar. Dua komponen utama ialah waktu konsentrasi (tc) dan intensitas curah hujan (I). Persamaan menurut (SNI 2415:2016) yang digunakan:

$$
\mathrm{Qp}=0,00278 \text { C.I.A }
$$

Qp $\quad$ : debit puncak banjir $\left(\mathrm{m}^{3} / \mathrm{s}\right)$

C : koefisien limpasan

I : intensitas hujan selama waktu konsentrasi ( $\mathrm{mm} / \mathrm{jam})$

A : Luas daerah aliran $(\mathrm{Ha})$

\section{Peta topografi}

Peta topografi memetakan tempat-tempat di permukaan bumi yang ketinggiannya sama dari permukaan laut menjadi garis-garis kontur, dengan satu garis kontur mewakili satu ketinggian. Kegunaan garis kontur adalah untuk mengetahui berapa tingginya suatu tempat dari permukaan laut. Garis kontur memiliki beberapa karakteristik, salah satunya adalah pada daerah yang landai garis kontur akan berjauhan, sebaliknya pada daerah yang terjal garis kontur akan saling merapat. Peta topografi juga menggambarkan sebanyak mungkin ciri-ciri permukaan suatu kawasan tertentu dalam batas-batas skala (Rostianingsih dan Gunadi).

\section{METODE PENELITIAN}

Tahapan penelitian dapat dilihar pada Gambar 2 sebagai berikut.

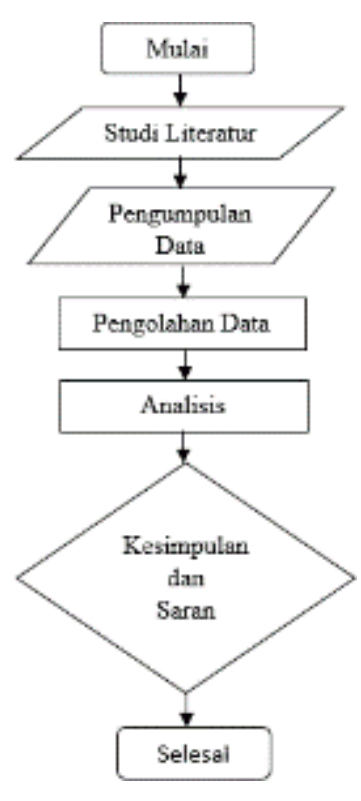

Gambar 2. Diagram alir

Dalam penelitian ini, data yang diperlukan:

- Peta Sebaran Titik Banjir di Kelurahan Tanjung Duren Utara dari Suku Dinas Sumber Daya Air Kota Jakarta Barat.

- Data Curah Hujan Harian Maksimum stasiun Meteorologi Kemayoran selama 10 tahun dari Badan Meteorologi Klimatologi dan Geofisika.

- Peta Jaringan Drainase di Kelurahan Tanjung Duren Utara dari Suku Dinas Sumber Daya Air Kota Jakarta Barat.

- Spesifikasi saluran eksisting di Kelurahan Tanjung Duren Utara dari pengukuran langsung di lapangan.

- Peta Topografi Kelurahan Tanjung Duren Utara dari Suku Dinas Sumber Daya Air Kota Jakarta Barat. 
Pengolahan data yang dilakukan adalah sebagai berikut:

- Mengambil data curah hujan maksimum harian setiap tahun.

- Melakukan pengujian kecocokan fungsi distribusi dengan menggunakan metode Chi-Square dan Kolmogorov-Smirnov.

- Melakukan perhitungan frekuensi curah hujan dengan distribusi yang sudah diuji dengan pengujian kecocokan fungsi distribusi.

- Menghitung kapasitas saluran drainase eksisting.

- Menghitung debit limpasan dengan metode Rasional.

Analisis data yang dilakukan adalah sebagai berikut:

- Menganalisis apakah debit saluran eksisting mampu menampung debit limpasan dengan metode Rasional atau tidak, jika tidak maka perlu direncanakan saluran drainase baru.

- Menganalisis saluran drainase rencana.

- Menganalisis topografi dari wilayah yang terdampak banjir.

\section{HASIL DAN PEMBAHASAN}

\section{Peta jaringan drainase dan daerah tangkapan air}

Peta jaringan drainase dan daerah tangkapan air untuk masing-masing saluran dapat dilihat pada Gambar 3 sebagai berikut.

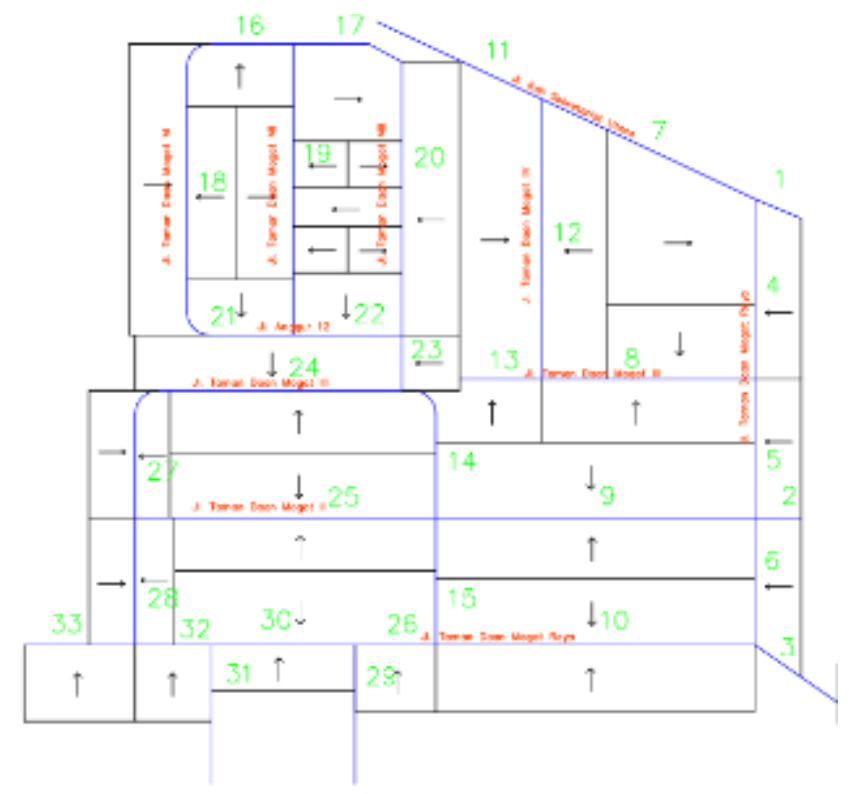

Gambar 3. Peta jaringan drainase dan daerah tangkapan air (Sumber: Suku Dinas Sumber Daya Air Kota Jakarta Barat, 2020)

\section{Topografi wilayah}

Peta topografi digunakan untuk menganalisis bentuk permukaan tanah pada daerah yang tergenang. Dapat dilihat pada Gambar 4, daerah tersebut merupakan dataran rendah berbentuk cekungan sehingga memungkinkan air dari daerah sekitarnya mengalir ke daerah tersebut ketika hujan terjadi. 


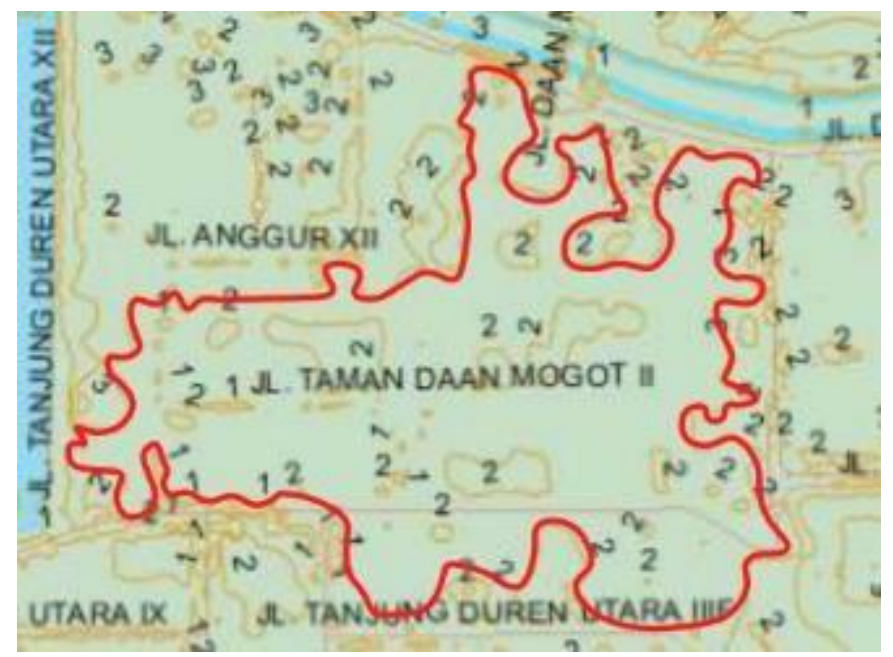

Gambar 4. Topografi wilayah Taman Daan Mogot (Sumber: Suku Dinas Sumber Daya Air Kota Jakarta Barat, 2020)

\section{Perhitungan curah hujan rencana}

Dilakukan pemilihan fungsi distribusi menggunakan metode Chi-Square dan Kolmogorov-Smirnov dapat dilihat pada Tabel 2 sebagai berikut.

Tabel 2. Uji Chi-Square dan Kolmogorov-Smirnov

\begin{tabular}{llllllll}
\hline \multirow{2}{*}{ No } & \multirow{2}{*}{ Distribusi } & \multicolumn{2}{c}{ Chi-Square } & \multirow{2}{*}{ Kesimpulan } & \multicolumn{2}{c}{ Kolmogorov-Smirnov } & \multirow{2}{*}{ Kesimpulan } \\
& & $\mathrm{X}^{2}$ & $\mathrm{X}^{2} \mathrm{Cr}$ & & Do & Dmax & \\
\hline 1 & Normal & 5,991 & 16 & Tidak Diterima & 0,41 & 0,1823 & Diterima \\
2 & Log Normal & 5,991 & 1 & Diterima & 0,41 & 0,1442 & Diterima \\
3 & Log Pearson III & 5,991 & 0 & Diterima & 0,41 & 0,1305 & Diterima \\
4 & Gumbel & 5,991 & 7 & Tidak Diterima & 0,41 & 0,4562 & Tidak Diterima \\
\hline
\end{tabular}

Distribusi yang akan digunakan adalah distribusi Log Pearson III.

Hasil perhitungan curah hujan rencana dengan metode Log Pearson III dapat dilihat pada Tabel 3 sebagai berikut.

Tabel 3. Curah hujan rencana

\begin{tabular}{ccccc}
\hline Periode Ulang & $\underline{\mathrm{k}}$ & $\underline{\log \mathrm{Rr}}$ & $\underline{\operatorname{Rr}(\mathrm{mm})}$ \\
\cline { 1 - 2 } 2 & $-0,033$ & 2,124095 & 133,07 \\
5 & 0,842 & 2,254952 & 179,87 \\
10 & 1,282 & 2,320754 & 209,29 \\
20 & $\underline{1,751}$ & $\underline{2,390893}$ & $\underline{245,98}$ \\
\hline
\end{tabular}

Berdasarkan Permen PU Nomor 12/PRT/M/2014 tentang Penyelenggaraan Sistem Drainase Perkotaan, periode ulang yang digunakan untuk daerah tangkapan air kurang dari $10 \mathrm{Ha}$ di kota metropolitan adalah 2 tahun (Kementerian Pekerjaan Umum).

\section{Analisis saluran eksisting}

Debit saluran eksisting dihitung dengan metode manning dan debit rancangan menggunakan metode rasional. Hasil perhitungan analisis saluran eksisting dapat dilihat pada Tabel 4 sebagai berikut. 
Tabel 4. Analisis saluran eksisting

\begin{tabular}{|c|c|c|c|c|c|c|}
\hline No & Posisi & Lebar Ek. (m) & Kedalaman Ek. (m) & Debit Limpasan & Debit Eksisting & Keterangan \\
\hline \multirow{2}{*}{1} & Kiri & & & & & \\
\hline & Kanan & 0,4 & 0,4 & 0,0107 & 0,0660 & MEMENUHI \\
\hline \multirow{2}{*}{2} & Kiri & 0,35 & 0,2 & 0,0015 & 0,0228 & MEMENUHI \\
\hline & Kanan & 0,45 & 0,6 & 0,0016 & 0,1277 & MEMENUHI \\
\hline \multirow{2}{*}{3} & Kiri & & & & & \\
\hline & Kanan & & & & & \\
\hline \multirow{2}{*}{4} & Kiri & 0,5 & 0,6 & 0,0282 & 0,2402 & MEMENUHI \\
\hline & Kanan & 0,35 & 0,7 & 0,0796 & 0,1681 & MEMENUHI \\
\hline \multirow{2}{*}{5} & Kiri & 0,5 & 0,4 & 0,0468 & 0,1461 & MEMENUHI \\
\hline & Kanan & 0,35 & 0,25 & 0,2661 & 0,0489 & TIDAK MEMENUHI \\
\hline \multirow{2}{*}{6} & Kiri & 0,4 & 0,8 & 0,0651 & 0,2400 & MEMENUHI \\
\hline & Kanan & 0,4 & 0,4 & 0,2553 & 0,1063 & TIDAK MEMENUHI \\
\hline \multirow{2}{*}{7} & Kiri & & & & & \\
\hline & Kanan & 0,2 & 0,4 & 0,0114 & 0,0235 & MEMENUHI \\
\hline \multirow{2}{*}{8} & Kiri & 0,3 & 0,6 & 0,1619 & 0,0957 & TIDAK MEMENUHI \\
\hline & Kanan & 0,3 & 0,6 & 0,0586 & 0,0957 & MEMENUHI \\
\hline \multirow{2}{*}{9} & Kiri & 0,3 & 0,4 & 0,0566 & 0,0603 & MEMENUHI \\
\hline & Kanan & 0,4 & 0,4 & 0,0701 & 0,0919 & MEMENUHI \\
\hline \multirow{2}{*}{10} & Kiri & 0,4 & 0,9 & 0,2488 & 0,3029 & MEMENUHI \\
\hline & Kanan & 0,4 & 0,4 & 0,2732 & 0,1175 & TIDAK MEMENUHI \\
\hline \multirow{2}{*}{11} & Kiri & & & & & \\
\hline & Kanan & & & & & \\
\hline \multirow{2}{*}{12} & Kiri & 0,4 & 0,4 & 0,0554 & 0,1383 & MEMENUHI \\
\hline & Kanan & 0,5 & 0,6 & 0,0949 & 0,3125 & MEMENUHI \\
\hline \multirow{2}{*}{13} & Kiri & 0,4 & 0,6 & 0,0053 & 0,1480 & MEMENUHI \\
\hline & Kanan & 0,4 & 0,6 & 0,0224 & 0,1480 & MEMENUHI \\
\hline \multirow{2}{*}{14} & Kiri & 0,7 & 0,4 & 0,0081 & 0,1446 & MEMENUHI \\
\hline & Kanan & 0,7 & 0,4 & 0,0736 & 0,1446 & MEMENUHI \\
\hline \multirow{2}{*}{15} & Kiri & 0,5 & 0,4 & 0,0072 & 0,0908 & MEMENUHI \\
\hline & Kanan & 0,5 & 0,5 & 0,0073 & 0,1197 & MEMENUHI \\
\hline \multirow{2}{*}{16} & Kiri & 0,4 & 0,6 & 0,0065 & 0,1428 & MEMENUHI \\
\hline & Kanan & 0,4 & 0,6 & 0,0218 & 0,1428 & MEMENUHI \\
\hline \multirow{2}{*}{17} & Kiri & 0,5 & 0,6 & 0,0114 & 0,1990 & MEMENUHI \\
\hline & Kanan & 0,5 & 0,6 & 0,0238 & 0,1990 & MEMENUHI \\
\hline \multirow{2}{*}{18} & Kiri & 0,3 & 0,5 & 0,0253 & 0,0705 & MEMENUHI \\
\hline & Kanan & 0,3 & 0,5 & 0,0489 & 0,0705 & MEMENUHI \\
\hline \multirow{2}{*}{19} & Kiri & 0,4 & 0,3 & 0,0148 & 0,0648 & MEMENUHI \\
\hline & Kanan & 0,4 & 0,4 & 0,0299 & 0,0926 & MEMENUHI \\
\hline \multirow{2}{*}{20} & Kiri & 0,5 & 0,6 & 0,0694 & 0,1735 & MEMENUHI \\
\hline & Kanan & 0,5 & 0,6 & 0,0333 & 0,1735 & MEMENUHI \\
\hline
\end{tabular}


Tabel 4. Analisis saluran eksisting (Lanjutan)

\begin{tabular}{|c|c|c|c|c|c|c|}
\hline No & Posisi & Lebar Ek. (m) & Kedalaman Ek. (m) & Debit Limpasan & Debit Eksisting & Keterangan \\
\hline \multirow{2}{*}{21} & Kiri & 0,3 & 0,5 & 0,0385 & 0,0562 & MEMENUHI \\
\hline & Kanan & 0,3 & 0,5 & 0,0468 & 0,0562 & MEMENUHI \\
\hline \multirow{2}{*}{22} & Kiri & 0,3 & 0,5 & 0,0897 & 0,0562 & TIDAK MEMENUHI \\
\hline & Kanan & 0,3 & 0,5 & 0,0457 & 0,0562 & MEMENUHI \\
\hline \multirow{2}{*}{23} & Kiri & 0,5 & 0,6 & 0,0777 & 0,1735 & MEMENUHI \\
\hline & Kanan & 0,5 & 0,6 & 0,1589 & 0,1735 & MEMENUHI \\
\hline \multirow{2}{*}{24} & Kiri & 0,8 & 0,6 & 0,2227 & 0,4566 & MEMENUHI \\
\hline & Kanan & & & & & \\
\hline \multirow{2}{*}{25} & Kiri & 0,6 & 0,7 & 0,0849 & 0,3266 & MEMENUHI \\
\hline & Kanan & 0,6 & 0,7 & 0,1663 & 0,3266 & MEMENUHI \\
\hline \multirow{2}{*}{26} & Kiri & 0,4 & 0,9 & 0,2594 & 0,3029 & MEMENUHI \\
\hline & Kanan & 0,4 & 0,4 & 0,2733 & 0,1175 & TIDAK MEMENUHI \\
\hline \multirow{2}{*}{27} & Kiri & 0,8 & 1 & 0,2265 & 0,8676 & MEMENUHI \\
\hline & Kanan & 0,4 & 0,5 & 0,0218 & 0,1366 & MEMENUHI \\
\hline \multirow{2}{*}{28} & Kiri & 0,75 & 0,8 & 0,4355 & 0,6037 & MEMENUHI \\
\hline & Kanan & 0,4 & 0,5 & 0,0200 & 0,1366 & MEMENUHI \\
\hline \multirow{2}{*}{29} & Kiri & & & & & \\
\hline & Kanan & & & & & \\
\hline \multirow{2}{*}{30} & Kiri & 2 & 1,3 & 1,3834 & 4,9993 & MEMENUHI \\
\hline & Kanan & 0,8 & 1 & 0,3062 & 0,9761 & MEMENUHI \\
\hline \multirow{2}{*}{31} & Kiri & & & & & \\
\hline & Kanan & & & & & \\
\hline \multirow{2}{*}{32} & Kiri & 2 & 1,3 & 1,9397 & 4,9993 & MEMENUHI \\
\hline & Kanan & 0,8 & 1 & 0,3040 & 0,9761 & MEMENUHI \\
\hline \multirow{2}{*}{33} & Kiri & 2,1 & 1,4 & 2,1617 & 5,8827 & MEMENUHI \\
\hline & Kanan & 0,9 & 1,1 & 0,7305 & 1,3010 & MEMENUHI \\
\hline
\end{tabular}

\section{Analisis saluran drainase rencana}

Dilakukan desain ulang untuk saluran eksisting yang tidak mampu menampung debit rancangan dapat dilihat pada Tabel 5 sebagai berikut.

Tabel 5. Analisis saluran rencana

\begin{tabular}{|c|c|c|c|c|c|c|c|c|}
\hline \multirow{2}{*}{ No } & \multirow{2}{*}{ Posisi } & \multirow{2}{*}{$\begin{array}{c}\text { Panjang } \\
\text { (m) }\end{array}$} & \multicolumn{2}{|c|}{ Baru } & \multicolumn{2}{|c|}{ Lama } & \multirow{2}{*}{$\begin{array}{l}\text { Debit } \\
\text { Rencana }\end{array}$} & \multirow{2}{*}{$\begin{array}{c}\text { Debit } \\
\text { Eksisting }\end{array}$} \\
\hline & & & Lebar (m) & Kedalaman (m) & Lebar (m) & Kedalaman (m) & & \\
\hline 5 & Kanan & 60 & 0,8 & 0,4 & 0,35 & 0,25 & 0,2785 & 0,0489 \\
\hline 6 & Kanan & 55 & 0,8 & 0,4 & 0,4 & 0,4 & 0,2785 & 0,1063 \\
\hline 8 & Kiri & 92 & 0,5 & 0,6 & 0,3 & 0,6 & 0,2062 & 0,0957 \\
\hline 10 & Kanan & 145 & 0,8 & 0,4 & 0,4 & 0,4 & 0,3078 & 0,1175 \\
\hline 22 & Kiri & 43 & 0,5 & 0,5 & 0,3 & 0,5 & 0,1197 & 0,0562 \\
\hline 26 & Kanan & 35 & 0,8 & 0,4 & 0,4 & 0,4 & 0,3078 & 0,1175 \\
\hline
\end{tabular}


Dari tabel diatas disimpulkan bahwa dimensi saluran drainase rencana dapat digunakan karena debit saluran drainase rencana lebih besar daripada debit rasional.

\section{Faktor lain penyebab banjir}

Selain kapasitas saluran ada juga penyebab lain yaitu:

- Topografi wilayah yang merupakan dataran rendah berbentuk cekungan sehingga air dari wilayah di sekitarnya mengalir ke wilayah Taman Daan Mogot.

- Terdapat sedimen di dasar saluran drainase dapat dilihat pada Gambar 5.

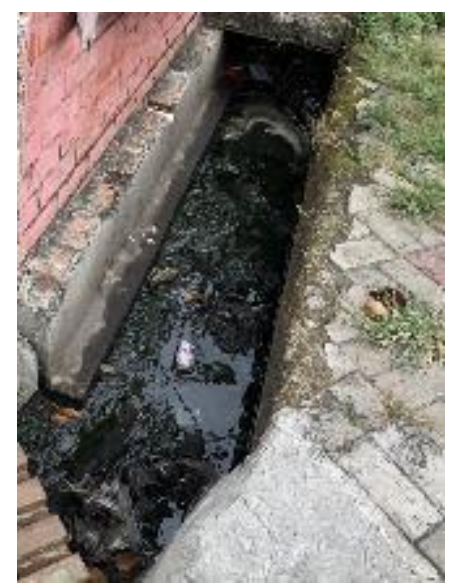

Gambar 5. Saluran drainase Jl. Taman Daan Mogot Raya

- Banyaknya sampah di saluran drainase dapat dilihat pada Gambar 6.

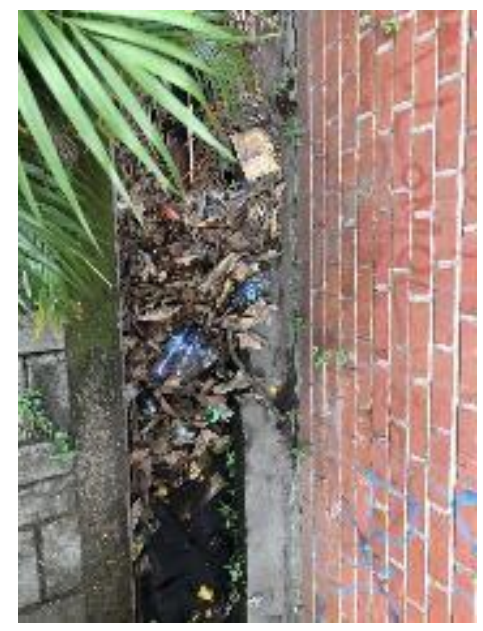

Gambar 6. Saluran drainase Jl. Taman Daan Mogot Raya

\section{KESIMPULAN DAN SARAN}

\section{Kesimpulan}

Setelah dilakukan penelitian ternyata ditemukan beberapa faktor yang menyebabkan genangan air terjadi di daerah Taman Daan Mogot. Terdapat 6 saluran drainase yang tidak mampu menampung debit dari hujan yang terjadi. Terdapat juga faktor lain yang menyebabkan genangan yaitu kondisi kontur wilayah yang merupakan dataran rendah berbentuk cekung, sedimen di dasar saluran serta sampah dengan ukuran cukup besar yang menghambat aliran air.

\section{Saran}

Berdasarkan analisis drainase yang dilakukan, disarankan untuk mengubah dimensi saluran sesuai dengan analisis saluran rencana, disarankan untuk melakukan normalisasi drainase secara rutin, karena mayoritas saluran memiliki 
sedimen di dasar saluran dan sampah dengan ukuran cukup besar yang mengganggu aliran air. Peran penting kepala daerah setempat juga diperlukan untuk melakukan sosialisasi agar masyarakat peduli dengan kualitas drainase. Perlunya peran organisasi pemuda setempat untuk memulai gerakan kepedulian terhadap lingkungan, agar masyarakat setempat menjadi sadar akan pentingnya kebersihan lingkungan.

\section{DAFTAR PUSTAKA}

Badan Standarisasi Nasional. “SNI 2415:2016.” Tata Cara Perhitungan Debit Banjir Rencana (2016).

Yosef Haryono, Sp. Buku Kuliah Drainase. Jakarta: Fakultas Teknik Universitas Tarumanagara, 2016.

Kementerian Pekerjaan Umum. "Penyelenggaraan Sistem Drainase Perkotaan.” 12/PRT/M/2014 (2014).

Lubis, Fadrizal. "Analisa Frekuensi Curah Hujan Terhadap Kemampuan Drainase Pemukiman Di Kecamatan Kandis." Program Studi Teknik Sipil Fakultas Teknik Universitas Lancang Kuning (2016).

Rachmawati, Azizah. “Aplikasi SIG (Sistem Informasi Geografis) Untuk Evaluasi Sistem Jaringan Drainase di Sub DAS Lowokwaru Kota Malang.” Jurnal Rekayasa Sipil Vol.4, No.2 (2010): 112.

Rostianingsih, Silvia dan Kartika Gunadi. "Pemodelan Peta Topografi ke Objek Tiga Dimensi.” Jurnal Informatika Vol.5 No.1 (2014): 14.

Suripin. Sistem Drainase Yang Berkelanjutan. Yogyakarta: Andy, 2004. 